\title{
The Influence of Interpersonal Conflict, Job Stress, and Work Life Balance on Employee Turnover Intention
}

\author{
Dr. Ahmad Fathulla Ahmad
}

\author{
Aynda Private Technical Institute-Business Administration, Erbil,Iraq \\ ahmadfathullaahmad@gmail.com
}

\author{
Received: 16 Feb 2022; Received in revised form: 20 Feb 2022; Accepted: 24 Feb 2022 \\ (2022 The Author(s). Published by TheShillonga. This is an open access article under the CC BY license \\ (https://creativecommons.org/licenses/by/4.0/)
}

\begin{abstract}
Staff providing services to clients is a common feature of the private sector. To remain competitive, the private sector must maintain high-quality and consistent services. The aim of this study to analyze the influence of interpersonal conflict, job stress, and work life balance on employee turnover intention. Quantitative research was applied to measure the current study. A random sampling method was used to gather data. The researchers distribute 120 questionnaires. 112 questionnaires were received but only 104 questionnaires were valid. The findings revealed that the value $B$ for Interpersonal conflict factor is .611 $(.611>0.01)$ therefore first research hypothesis was supported. The value B for Job stress factor is .599 (.599<0.01) therefore second research hypothesis was supported. The value B for Work life balance factor is .643 (.643>0.01) therefore third research hypothesis was supported. Although the literature shows that turnover has a negative impact on many organizations, this study provides evidence that this relationship has an impact on the pesticide sector in this region.
\end{abstract}

Keywords - Employee Turnover Intention, Interpersonal Conflict, Job Stress, Work Life Balance.

\section{INTRODUCTION}

Every organization's most valuable asset is its people. Human interaction is critical because organizations are made up of people, not technology or structure. A consulting firm assesses high human development indices for the best-performing businesses. People nowadays are more burdened to maintain a balance between their personal and professional lives in order to maintain high performance (Park et al., 2020). Work-family conflicts are on the rise in today's world, and they are not limited to a single organization. The conflict has negative consequences, particularly in Asian countries such as the KRG, which is a collectivist society. Work and family are two of the most important aspects of our daily lives, and they have a significant impact on our understanding of human nature. Researchers have known for a long time that these variables have a correlation that leads to conflict. Work-family conflict occurs when the demands of one role interfere with one's ability to meet the demands of another role in another domain (Chuan-Chiew et al., 2018). Work-family issues have become increasingly important in the modern world for employees, families, and organizations, as little time for family responsibilities and obligations increases job stress at the home-work interface. Work-family conflict is a type of inter-role conflict in which the role pressures from each domain are in some way incompatible (Aboobaker \& Edward, 2020). Work-family conflicts arise when the expectations of one domain are incompatible with the demands of the other domain. As a potential job stressor, the conflictive interface between home and work (Mullen et al., 2018). The nature and direction of work-family conflict, hypothesizes that time-based work interferes with family and family interferes with work, i.e., concluded that employees experiencing job stress leads to turnover (Wood et al., 2020).

Since the private sector is labor intensive, high employee turnover rates have been a constant and difficult challenge for private sector human resource management because low retention rates increase organizational costs, compromising organizations' competitive advantage (Raharjo et al., 2019). How to improve employees' organizational commitment and boost top employee retention is a major task for today's hospitality industry. Internships have become a major source of labor for entry-level positions in the hospitality industry due to staff shortages. According to research, internships help students transition from school to the workplace by providing them with hands-on experience, improving their professional competence, and expanding their employment opportunities. Internships reduce labor 
costs and burdens in the private sector (Hutagalung et al., 2020).

Employees are valuable assets to the organization, and the company makes every effort to keep key performers on board. As a result, clothing companies offer attractive benefits to their employees such as competitive salaries, transportation, and medical care, among other things. Employee turnover, on the other hand, is a critical issue in maintaining the industry's competitive advantages (Afzal et al., 2021). As a result, turnover is a serious threat to the organization's productivity.

Job stress is a part of everyone's existence, and everyone goes through a cycle of job stress in their daily lives. It becomes a threat when a person encounters it at work, so it becomes a critical concern for both the employer and the employees. There are many theories and definitions of job stress because it is a difficult topic to address, and the level of job stress varies from person to person, with the same person reacting differently in the same situation and different people reacting the same way in different situations (Yildiz et al., 2021). Job stress, according to the author, is a psychological and physiological state that occurs in a specific environment. Job stress occurs when a person experiences pressure, tension, or any other negative emotion such as anxiety or anger (Jiang \& Shen, 2018).

An organization's success is heavily reliant on its employees. If there is a risk of employees quitting, the organization will suffer long-term consequences of this major challenge. High turnover has a negative impact on the organization's cost and profitability (Hassan, 2014). According to Gim \& Ramayah, (2020), a job stressed situation occurs when a person suffers from mental and physical illness as a result of unfavorable circumstances. They also mentioned noise, dim lighting at work, high job demands, role overload, role ambiguity, lack of sleep and time pressure, and everyday workload, contradictory demands, insufficient resources to perform well, inability to make decisions, and conflicts. All of these job stress dimensions lead to dissatisfaction, poor health, and high job stress. KRG is a developing country that relies on agriculture. Following that, $70 \%$ of its population is engaged in private sectors, which contributes significantly to national income. Pesticides are considered a backbone in agriculture, and Punjab is famous for its agriculture because the majority of the population is engaged in this profession, and employees in the pesticides sector are always busy developing and introducing new and effective products. The majority of employees in this sector work in the field and interact with employees. This industry has an impact on people, food commodities, the environment, and the economy. Previous studies on turnover have focused on the dissimilar factors that cause turnover before addressing the issues of how to retain employees so that the turnover rate can be reduced. The organizations depleted a high cost of employee retention. Previous research has also classified the various factors that influence turnover. According to current literature, there is a plentiful and growing source of information about job stress and turnover. Rather than investigating the unfavorable impact of job stress on employee turnover, a good reason is to discover or investigate the impact of job stress on the intention to leave the organization (Holland et al., 2019). The fast-paced world and ever-changing environment in private sector organizations necessitate a low turnover rate for successful operations at a low cost. Managing multiple roles across multiple domains increases interpersonal and intrapersonal conflicts among employees, which can lead to Interpersonal conflict (Zahra et al., 2018). Interpersonal conflict, according to the researchers, creates a path to labor turnover and has a positive relationship with Turnover Intention (TI) (Pathak, 2018). However, Alias et al., (2018) discovered that interpersonal conflict has no effect on employee turnover intention. As a result, there are contradictory arguments. It was discovered that any disruption between work and family causes worker dissatisfaction. This dissatisfaction may eventually influence his desire to leave his current job (turnover intention). Work job stress, in addition to work-life balance, can have an impact on a worker's job satisfaction. Work job stress, according to Perumal et al., (2018), is a feeling of dijob stress felt by workers in the face of their work that can be triggered by working conditions, excessive burdens, and interpersonal relationships with colleagues. High levels of work job stress result in a strong desire to leave the workplace (Perumal et al., 2018). Job satisfaction, like work job stress, is regarded as an important predictor and has a significant inverse relationship with turnover intention (Navajas-Romero et al., 2020). Adequate flexibility can solve the problem of worklife balance (Lestari et al., 2021), because the goal of flexible work arrangements is to improve inter-role conflict, which will attract workers, particularly those who face competing demands (Irawanto et al., 2021). Work-life balance policies aid in job stress reduction (Saerang et al., 2020). Organizations should implement policies that assist employees in balancing their work and personal lives (Kim \& Kim, 2021). The greater the physical/psychological symptoms and turnover intentions, the greater the workfamily imbalance. Many prominent researchers have linked work-family conflict to a variety of problems, including domestic violence, poor physical activity, poor eating habits, poor emotional health, excessive drinking, substance abuse among women (Vasumathi et al., 2019). Workfamily conflict is a type of inter-role conflict in which work 
and family demands are mutually incompatible, making it difficult to meet demands from both domains, resulting in job stress, which is essentially a form of unpleasant emotion that has the potential to increase employee turnover rate. According to Giao et al., (2020), work-family conflict by explaining the conditions under which spillover between the work micro system and the family micro system is positive or negative. For example, if work-family interactions are rigidly structured in time and space, spillover in terms of time, energy, and behavior is generally negative.

Many studies have been conducted to demonstrate the impact of work-life balance, job stress, and job satisfaction on turnover intention. The majority of the research was conducted in the private sector. Because of the unique characteristics of KRG anti-corruption institutions, this research was conducted to determine whether there were similarities in results with previous research or differences due to the uniqueness of the research object's characteristics. Conflict theorists frequently assume that conflict is a natural, functional, dysfunctional, and inherent human and organizational relationship phenomenon (Son \& Ham, 2020). Interpersonal conflict is a source of job stress that has an impact on organizational outcomes. Along with organizational outcomes, interpersonal conflict can have a negative impact on employee attitudes and behaviors (Haar \& Brougham, 2020). According to the conceptual model of Zhou \& Gao, (2020), interpersonal conflict is a job stressor that is consistently related to organizational politics Job stress. The essence of this association is that politics is a self-serving behavior that can endanger the self-interest of others. Conflict occurs when a threat is met with retaliation. The presence of conflict is an essential component of organizational politics Job stress (Viegas \& Henriques, 2021). Based on conceptual frameworks (Chang et al., 2019), this study aims to empirically investigate the relationship between these job stressors (interpersonal conflict and Job stress of organizational politics) and job attitudes and behaviors. Extensive research has been conducted on two important constructs: conflict and organizational politics Job stress. Conflict is a phenomenon that has an impact on almost every level and process in an organization (Fadillah et al., 2022). Politics, on the other hand, is a widespread phenomenon in almost every organization. Conflicts have negative consequences and are harmful to both individuals and organizations. Job stresss of organizational politics have negative consequences that are harmful to both individuals and organizations. Conflict can be both functional and dysfunctional. Organizational politics is both functional and dysfunctional in nature. This resemblance between two constructs demonstrates their close relationship ( $\mathrm{Li}$ et al., 2021). The primary goal of my research thesis is to identify any potential relationships between these two important variables, as well as to investigate the conflict-politics outcome, to see how the two constructs influence attitudes and behaviors such as job stress, intention to quit, interpersonal and organizational workplace deviance (Gragnano et al., 2020).

Many researchers have paid attention to workplace turnover. Managers and researchers regard turnover as a problem due to the costs associated with it (Mohd Pauzi et al., 2021). According to Califf \& Brooks, (2020) discovered that the impact of turnover on a business can be quite costly in a variety of ways. Replacing a long-tenured manager is quite visible; however, replacing a manager, particularly one who is marginally effective, has positive effects that outweigh the cost. Increased working hours, according to Gholitabar et al., (2020), are a source of work job stress and intentions to leave. Since the arrival of multinational corporations in our country, research has served as a pillar. Interpersonal conflict has a significant impact on turnover intentions because marketing executives perceive it to be difficult and complex to handle both situations effectively. Job stress has both positive and negative aspects (Thevanes \& Harikaran,2020). Job stress has been linked to lower worker and organizational performance by Van der Heijden et al., (2018) discovered a positive relationship between emotional exhaustion and intention to leave, whereas Ola et al., (2019) believe job stress is a major cause of employee disability. Because the difficulty of balancing work and family demands has grown rapidly, many people see familyfriendly policies as an important attraction and retention strategy. Those who try to leave work job stress at work or keep lingering job stress to themselves; job stress is likely to have a pernicious effect on emotional balance (Cho et al., 2019).

\section{LITERATURE REVIEW}

\section{Interpersonal conflict}

Interpersonal conflict is regarded as a significant source of job stress in organizational settings. Interpersonal conflict has been linked to a variety of negative outcomes in employees as a work job stressor, including an increase in the prevalence of psychosomatic issues (Amalia \& Zakiy, 2021). According to Panojan et al., (2019), when attempting to improve employees' Job stresss of their jobs, there should be a focus on both interpersonal relationships between colleagues and interpersonal relationships between superiors and subordinates. According to Ludiya, (2018) general theory of social relations, Communal Sharing relationships, one of four models of social relations, hold that when individuals share certain characteristics, identification with those characteristics causes them to be kind and altruistic toward one another. People are 
predisposed to seek this type of identification and perceive certain obligations to be entailed by it (Els et al., 2021). People feel closer to and want to be treated well by those with whom they share personal characteristics, according to a similar viewpoint. As a result, conflict is more likely to occur between people who have different cultural backgrounds, attitudes, values, Job stresss, and so on (Bontrager et al., 2021). According to Donovan et al. (1998), the quality of interpersonal relationships between workers and managers has a direct impact on job satisfaction and intention to leave. Al Doghan, (2020) concluded that there is a significant positive relationship between interpersonal conflict and cynicism, and a significant negative relationship between knowledge sharing and cynicism in their study "the effect of interpersonal conflict and knowledge sharing on organizational cynicism. Moquin et al., (2019) discovered that workplace cynicism and a high turnover rate have strong positive relationships in their study of "The relationships among Organizational Cynicism, Job Insecurity, and Turnover Intention.

Interpersonal conflict is commonly defined as the parties' awareness of differences, contradictory desires, and interpersonal incompatibilities (Romeo et al., 2020). Conflict is defined by Andrade et al., (2021) as a specific type of social interaction process between parties who have mutually exclusive or incompatible values. Park et al., (2020) examined a multidimensional framework for conflicts that included Emotional versus Intellectual, compromise versus win, and task versus interpersonal conflict. Chuan-Chiew et al., (2018) distinguished conflict based on the substance of the assignment and the interpersonal relationship. Interpersonal conflict is defined as a disagreement between two people who believe they have incompatible goals. Conflict and its consequences Job stress is another important construct in this study. When key responsibilities are delegated to individuals who lack the necessary authority, job stress ensues (Aboobaker \& Edward, 2020). Job stress occurs when an employee feels embarrassment in an organization. When work demands exceed the individual's belief in their ability to manage, the individual becomes job stressed. Job stress is caused by job stressors (both individual and organizational), which result in negative physical, psychological, or physiological reactions (Mullen et al., 2018). Conflict is one of seven situational job stressors. Work and nonwork conflict increase job stress in the workplace and affect employees' attitudes and behaviors. According to Wood et al., (2020), one factor that causes job stress in an organization is work conflict, and work conflict is significantly related to job stress. Interpersonal conflict is the result of inter-personal incompatibility, which typically includes affective factors such as friction, tension, animosity, and impatience (Raharjo et al., 2019). According to this argument, workplace job stress can be caused by interpersonal conflict. The purpose of this study is to conduct an empirical investigation into the relationship between interpersonal conflict and job stress. As a result, this study hypothesizes that interpersonal conflict is related to job stress in a positive way.

Workplace deviance, according to Hutagalung et al., (2020), is voluntary behavior of organizational members that violates significant organizational norms, endangering the well-being of the organization and/or its members. Organizational deviance is a reaction to vexing job stressors, which can include social, financial, and working conditions. Deviant behavior occurs when an individual or group in an organization violates or breaks the rules, traditions, or internal regulations. Workplace deviance, Aggressive Behavior, Counterproductive Behavior, and Anti-social Behavior are some of the terms used by researchers to describe these behaviors (Afzal et al., 2021). According to Yildiz et al., (2021) framework, workplace deviance is classified into two types: interpersonal workplace deviance and organizational workplace deviance. Individuals and employees of an organization who engage in deviant behaviors such as sexual harassment and verbal and physical aggression are examples of interpersonal deviance behavior. While organizational deviance is defined as behavior between employees and organizations that engages in activities such as theft, putting in little effort at work, and sabotage. When members of an organization face conflict, they may exhibit deviant behavior (Jiang \& Shen, 2018). It is difficult for professionals to avoid conflicts in an organization because they can lead to employees engaging in deviant behavior.

The intention to quit is another important construct in this study. The decision to leave an organization is defined as an employee's intention to quit. Employees may leave an organization voluntarily or involuntarily (for a variety of reasons): voluntarily turnover may be due to an unfavorable work environment, greater or career objectives, or more appealing financial sources, whereas involuntary turnover is typically from an employer or organizational side. Involuntary turnover can occur when an organization wishes to terminate an employee due to incompatibility or retire an employee due to old age; death is also included in involuntary turnover (Gim \& Ramayah, 2020). Employee turnover has significant consequences. When an employee leaves an organization, the organization is responsible for the costs of selecting, recruiting, and training the new employee. Employee turnover has indirectly lowered morale among remaining employees and resulted in a loss of social capital. Employee turnover is difficult to quantify, 
especially when the employee is a high performer with a high level of knowledge and skill (Holland et al., 2019). One goal of my research is to look into the factors that influence a person's decision to quit smoking; interpersonal conflict could be one of these factors. The literature strongly supports the existence of a positive relationship between interpersonal conflict and intention to quit. This study is an attempt to delve deeper into the relationship between interpersonal conflict and intention to quit (Zahra et al., 2018).

Interpersonal conflict, according to Pathak, (2018), is informal, ostensibly parochial, typically divisive, and above all, in the technical sense, illegitimate - sanctioned neither by formal authority, accepted ideology, nor certified expertise. Alias et al., (2018) associated politics with conflict and referred to it as the political arena. Perumal et al., (2018) identified seven political factors: power acquisition, hidden motive, conflict, acting against organization, formal, informal, and illegal behavior. According to Mallika \& Das, (2020), there are controversies in defining the concept of politics, and there is no general or basic definition that explains the complexity of this concept. However, Navajas-Romero et al., (2020) argue that politics is a three-dimensional construct. Lestari et al., (2021) defined three dimensions: first, general political behavior," in which individuals engage in self-serving behaviors to achieve desired outcomes; second, go along to get ahead, in which individuals remain silent and act passively for their own benefit; and third, "go along to get ahead. Third, pay and promotion policies," which involve individuals who are involved in policy implementation and react politically in the decision-making process (Irawanto et al., 2021). When the collective demands of an individual's two roles are incompatible, interpersonal conflict occurs. As a result, participation in one role makes participation in the other role more difficult. According to Saerang et al., (2020), conflict occurs when time devoted to the requirements of one role, strain from participating in a role, or specific behaviors required by a role make fulfilling the requirements of another difficult. There are various types of interpersonal conflict that arise from various sources. According to Kim \& Kim, (2021), the most significant interpersonal conflict arises from complex workplace issues such as managing change, supervisory and technical competencies, leadership, roles and accountability, and so on.

Interpersonal conflict studies have primarily focused on the conflict between people's work and other life roles. The interpersonal conflict that occurs when work roles conflict with family roles and family related roles conflict with work roles. The concept of "work-life balance" meant different things to different people. It is widely acknowledged that there is a clear relationship between interpersonal conflict and work-life balance. Because achieving work-life balance is dependent on managing or reducing conflict among various roles (Vasumathi et al., 2019).

\section{Job Stress}

Job stress is defined as the body's nonspecific response to a stimulus or event (Giao et al., 2020). Job stress is defined as pressure or anguish resulting from difficult situations (Son \& Ham, 2020). Job stress refers to workers' inability to adapt to their jobs and, as a result, involves some biological and psychological reaction (Haar \& Brougham, 2020). Several studies on job stress have been conducted on various occupations. Job stress on family life may arise from both the schedule and the content of work, according to (Zhou \& Gao, 2020), while (Viegas \& Henriques, 2021) believe it is unavoidable. It has a negative impact on both the individual and the organization. It prepares the body for defense. Work overload has a strong influence on work exhaustion and causes a variety of diseases sooner or later. Three scales measuring general job stress, emotional job stress, and social job stress with their consequences are included in general job stress. Job stress is caused by a misalignment of expectations between management and customers (Chang et al., 2019). According to Fadillah et al., (2022), reducing job stress increases employee productivity. Job stress can increase turnover. Job stress is a type of unpleasant emotion that, according to Li et al., (2021), has the potential to increase employee turnover. According to Gragnano et al., (2020), "increased withdrawal of retained employees would be evident in job dissatisfaction, resulting in low job commitment, or works job stress as a result of increasing job tension, or a combination representing both dissatisfaction and job stress. According to Mohd Pauzi et al., (2021), work load increases due to large duties, insufficient staffing, and additional work handed down by management, workers become more job stressed and thus quit, particularly during critical incidents. According to Califf \& Brooks, (2020), job-related tension has a causal impact on job satisfaction, which influences turnover intentions. According to Gholitabar et al., (2020), emotional exhaustion increases turnover intention, whereas work satisfaction decreases turnover intention. Thevanes \& Harikaran,(2020) discovered a significant relationship between job stress levels and intention to quit. Job stress and its effects on psychiatric symptoms are also linked to an employee's proclivity to quit. Increased job stress leads to increased employee turnover intentions. Job stress is related to the intention to leave one's current job. Job stress has a significant positive effect on turnover intentions (Van der Heijden et al., 2018).

Job stress is defined as an emotional and psychophysiological reaction to noxious and aversive aspects of 
work, work environments, and work organizations. It is a state characterized by high levels of arousal and job stress, as well as feelings of helplessness. Job stress is a nonspecific bodily reaction to a stimulus or event. Job stress can also be defined as pressure or anguish caused by difficult situations (Ola et al., 2019). Job stress is defined as workers' inability to adapt to their jobs and, as a result, involves some biological and psychological reactions. Jobrelated stress has a direct effect on job satisfaction, which in turn influences turnover intentions. Similarly, emotional exhaustion increases turnover intention, whereas work satisfaction decreases turnover intention. Many studies have also found a link between job stress and poor worker and organizational performance. Many studies have been conducted to investigate the positive relationship between job stress and intention to leave. Additional work burdened by management causes more job stress among employees, and as a result, they quit, especially during critical incidents. Emotional exhaustion increases turnover intention, whereas work satisfaction decreases turnover intention (Cho et al., 2019). Job stress and its effects on psychiatric symptoms are also linked to an employee's proclivity to quit. Job stress is related to the intention to leave one's current job. The amount of job stress has a significant positive effect on intention to leave. The resource theory conversation is a supporting theory in the relationship of work-family conflict and turnover intentions via job stress as a mediator. According to this theory, people strive to protect and build resources such as objects (money, house), conditions (quality of one's roles, external support), energies (time and vigor), and personal characteristics (beliefs such as a positive outlook). When these resources are lost or threatened, psychological job stress develops, which eventually leads to high turnover intentions. Similarly, in the opinion of, job stress has a significant positive effect on turnover intentions (Amalia \& Zakiy, 2021). Furthermore, work-family conflict causes job stress, which leads to high turnover intentions.

Over the years, many theories about job stress have been developed by various researchers, and these theories provide various frameworks for understanding job stress and its various features or dimensions. All of these theories have one thing in common: they all explain job stress as "an active and powerful process operating between an individual and his or her environment." Some factors that contribute to job stress include increasing education level, work-life balance, work environment, marital status, financial constraint, job insecurity, lack of control, and poor time management. These specific factors are linked to the intention to quit (Panojan et al., 2019). Ludiya, (2018) defined job stress as a model consisting of emotional and psychological states or reactions that occur in response to a requirement within or outside the organization. As a result, these demands become job stressors, which cause job stress because the demands and situations become out of one's control and threaten. As a result, job stress is the result of a mismatch between one's expectations and one's actual working conditions. In other words, it is defined as the gap between professional demands and people's ability to meet them.

Els et al., (2021) defined job stress as a mismatch between the environment and the individual, as well as an interaction between the situation and the individual. Job stress occurs when an individual is unable to cope with the demands and pressures of his or her job. Job stress varies from person to person and situation to situation. Human beings react to job stress both physically and mentally; for example, if a person feels a situation negatively, it creates job stress in his/her mind, whereas a person does not get job stressed if he/she feels a situation positively. Bontrager et al., (2021) conducted a study on the occupational job stress index. They claimed that job stress occurs when the demands of the job become uncontrollable and the employees are unable to cope with them. Workloads have an impact on employees' well-being, time, and vigor. As the number of employees grows, they are unable to strike a balance between mental and physical health and personal or impersonal issues. Long working hours, interpersonal conflicts, workplace environments, Interpersonal conflict, employment status, job demand, job control, and participation in decision making are all examples of job stressors. All of these job stressors have a negative impact on employees' intention to leave their jobs (Al Doghan, 2020).

Moquin et al., (2019) investigated the impact of occupational job stress on employee turnover. Job stress is a physical and psychological state that occurs in a variety of situations and can be regarded as an important aspect of a person. They attempted to show, using literature, that job stress has a negative impact on employees' personal lives. Employee productivity, self-esteem, and performance all suffer as a result of job stress. They studied the private sector because job stress is high in this sector. The results are measured using principal component factor analysis. It is investigated whether employees who are affected by occupational job stress intend to change jobs. Furthermore, turnover intention is regarded as an interpreter of genuine turnover. Because of the high level of job stress, turnover intentions are high. Job stress stems from a variety of sources and factors, including difficulties at home, with tasks, pay, and unfair treatment, inconsistency with job conscientiousness, organizational culture, and a lack of support (Romeo et al., 2020). 


\section{Work-Life Balance}

Work-life balance is defined as a type of inter-role conflict in which work and family demands are mutually incompatible, making it difficult to meet demands from both domains (Andrade et al., 2021). This conflict has an impact on psychological functioning (Schieman, McBrier \& Gundy, 2003). Employers who emphasize the importance of work-life policies, according to Park et al., (2020), send a signal throughout the organization that work-life issues are important. Work-life policies are artifacts or top-level indicators of an organization that prioritize work over family or family over work. According to Chuan-Chiew et al., (2018) turnover is an important issue for organizations, and friendly work life policies to reduce turnover. Aboobaker \& Edward, (2020) also supports friendly policies to reduce turnover, while Mullen et al., (2018) found no significant relationship between interpersonal conflict and turnover intentions. Organizations are looking for policies that can be implemented to reduce turnover. Some researchers in KRG, for example, Wood et al., (2020), have recently attempted to emphasize the importance of work life policies. Work-life programs are efficient in improving attitudes and effective in reducing work-family conflict. Companies are becoming more aware of the importance of work-life balance and are implementing more accommodating work-life policies. High turnover rates jeopardize continuity of care and jeopardize workers' ability to perform critical case management functions. The most effective organizational responses to work-family conflict and turnover are those that combine work-family policies with other human resource practices, such as work redesign and commitment-enhancing incentives. Work-Life balance is an important business strategy for reducing employee turnover and improving overall firm performance. More adaptability can help to solve the problem of work-life balance (Raharjo et al., 2019). Because the goal of flexible work arrangements is to improve inter-role conflict, it also seems reasonable to assume that flexible arrangements will be appealing to workers, particularly those facing competing demands. Work-life balance policies aid in job stress reduction (Hutagalung et al., 2020). While Afzal et al., (2021) regards it as a precursor to organizational commitment. Implement such changes in your organization that fulfill the basic policies and requirements of employees, so that the turnover intentions ratio can be easily reduced. Organizations must design and implement benefits and policies to assist employees in balancing work and life (e.g., flexible work schedules, dependent care supports).

Work-life balance has been found to be very important in attracting and retaining talent in recent years. Work-life balance refers to an employee's ability to strike a balance between work, home, and other responsibilities. Work-life balance is defined as achieving satisfactory experiences in all areas of life. To achieve satisfying experiences in all domains of life, personal resources such as energy, time, and commitment must be distributed evenly across all domains. If employees' responsibilities, pressures, and obligations at work are too great, or if working hours are too long, and resources are not distributed evenly, they may impair their quality of life and lead to poor physical and mental health. As a result, the employee mentality that must be emphasized in organizational management is work-life balance (Yildiz et al., 2021). Work-life imbalances, according to Holland et al., (2019), can lead to problems such as reduced employee productivity, low morale, lateness, absence, and so on, as well as employee turnover. Employees who can strike a good balance between work and personal life will benefit both the company and themselves in the long run. According to Zahra et al., (2018) work-life balance is defined as individuals' psychological satisfaction, and it can significantly improve self-efficacy. Work-life balance is negatively correlated with the number of overtime hours worked and the individual's working hours. The greater the number of overtime hours and working hours, the more unbalanced work and life will affect the employee's willingness to stay and work productivity. Organizational commitment and growth are critical for an individual's career advancement. It is mandatory for an individual to fulfill societal commitments, social responsibilities, and contribute time to the well-being of society. Commitment to self-development and good health, on the other hand, are required for living a peaceful life. Mismanagement of personal, societal, and organizational commitments can have serious consequences in all three areas. While definitions and explanations vary, work-life balance can be broadly associated with equilibrium, or the maintenance of a general sense of harmony in life. Work-life balance had a significant impact on an employee's overall job satisfaction, organizational commitment, and willingness to stay (Pathak, 2018). Poor work-life balance has a negative impact on employees' health and well-being, as well as the performance of organizations. As a result, an imbalance between work and personal life causes increased job stress, which may lead to increased turnover intention among employees. As a result, employees' ability to achieve work-life balance with organizational support should result in higher job engagement, greater commitment, improved job performance, and a lower turnover rate. Work-life balance, according to these findings, is associated with organizational commitment and influences intention to stay. Furthermore, organizational commitment's positive effect on turnover intention is mediated by organizational 
commitment reinforcing work-life balance (Alias et al., 2018).

\section{Turnover Intention}

Turnover intention is defined as an individual's desire to leave a company. Turnover intention is broadly defined as an attitudinal (considering leaving), decisional (planning to leave), and behavioral (looking for a new job) process (Perumal et al., 2018). Turnover intention is the conscious desire to seek out other options in other organizations. Employee turnover occurs when employees leave their jobs voluntarily and must be replaced. Many researchers have paid attention to workplace turnover (Mallika \& Das, 2020). Managers and researchers regard turnover as a problem due to the costs associated with it. Turnover intentions have been extensively researched in the OB literature. When employee performance is consistently poor, threats or punishment led to many people being fired (involuntary turnover) or being threatened and punished enough to leave (voluntary turnover). Similarly, self-actualization and interpersonal relationships can have a direct impact on employees' affective reactions to their jobs, which in turn influences their intention to leave (Navajas-Romero et al., 2020). Turnover Intentions has a strong positive relationship with interpersonal conflict, according to Lestari et al., (2021). Similarly, turnover intention is positively related to job stress (Irawanto et al., 2021). According to these studies, as job stress levels rise, individuals are more likely to leave their jobs and seek new opportunities, either within the field or in another industry. The rate at which employees leave a company is referred to as turnover. The higher the turnover rate, the higher the cost of recruitment, training, socialization, experience, and so on for organizations. Several behavioral consequences of decreased job involvement, poor performance, and dissatisfaction would result in turnover. Many researchers consider turnover to be an important issue for organizations and advocate for work-life policies that promote a positive work environment. Companies are becoming more aware of the importance of work-life balance and are implementing more accommodating policies. A high turnover rate reduces continuity of care and jeopardizes workers' ability to perform optimal management functions. Many researchers believe that work-life balance policies can help to reduce job stress and turnover intention (Saerang et al., 2020).

Turnover intentions to leave are positively related to turnover. According to Kim \& Kim, (2021), job turnover research has focused on the relationship between the intention to leave the organization and the actual leaving. The greater the complementarity, the greater the effect on satisfaction and intentions to leave (turnover intentions). According to Vasumathi et al., (2019), turnover typically refers to the separation of an employee from the firm. Giao et al., (2020) extended the intent-to-turnover concept to include two internal turnover variables (intent-to-leave the location and intent-to-leave the job) in addition to the more commonly used external turnover measure (intent-to-leave the organization). One of the recent research approaches in the organizational turnover literature has been focusing on the causes of employee intentions to stay or leave. According to Son \& Ham, (2020), when employee performance is consistently poor, threats or punishment cause many individuals to be dismissed (involuntary turnover) or threatened and punished enough to leave (voluntary turnover). Similarly, Haar \& Brougham, (2020) discovered that self-actualization and interpersonal relationships can directly influence employees' affective reactions to their jobs, which in turn influences their turnover intentions. Turnover is a critical issue for management, particularly in the tight labor markets that characterize the twenty-first century. The emphasis placed on the concept of organizational commitment indicates that it is linked to turnover. Traditional turnover factors such as organizational commitment and work exhaustion were found to be related to turnover intention (Zhou \& Gao, 2020). The goal of 'effective turnover management' requires organizations to achieve a high level of sophistication in order to selectively influence the turnover process. According to Viegas \& Henriques, (2021), turnover is important because of its relationship with organizational performance. According to Chang et al., (2019), normal worker turnover is beneficial to growth and development. Other research indicates that the best performers are the most likely to leave because external opportunities are plentiful. According to Fadillah et al., (2022), turnover intention does not always result in turnover because a number of other factors enter the equation. Li et al., (2021), assumed that turnover intentions would eventually translate into turnover behavior over time. Several behavioral consequences of decreased job involvement, poor performance, and low job satisfaction would undoubtedly lead to absenteeism and turnover. Although the role of intentions in the turnover process was supported and even highlighted in the study, the direct effect of personal and organizational variables on turnover or intentions was called into question. The preceding study demonstrates the significance of turnover intentions in various labor markets. Management styles differ, and turnover issues could be future research topics (Gragnano et al., 2020).

Turnover is a type of behavior that describes the procedures for leaving or replacing employees in an organization. Turnover is not a new concept in management, but it is an important issue in human resource management that piques the interest of public administration and labor relations 
practitioners all over the world. As competition heats up, businesses must devise strategies to keep their employees (Mohd Pauzi et al., 2021). According to Califf \& Brooks, (2020), turnover intention has been extensively researched and validated, but the turnover intention scale needs to be validated. Turnover is the deliberate decision to leave an organization. It should also be noted that turnover is a deliberate intention or part of an employee's strategy to get out of their current situation. Turnover and job demand have an indirect relationship. When there are a lot of job demands, job stress arises, which leads to intentions to leave. The job resource also increases the likelihood of turnover. Turnover is influenced by a variety of personal and impersonal factors, and a person leaves a job when he or she can easily find another job or has other opportunities. The intention to quit has always had a high cost and a negative outcome. According to Gholitabar et al., (2020), there are a few instruments available in the literature to measure concepts such as absenteeism, turnover, and retention. Some factors, such as rewards, workplace fairness, bullying and harassment, poor management relationships, management support, supervisor, safety and security, coworker relationship, and others, make it easy to predict whether employees will stay or leave. The researcher employed qualitative techniques to identify the factors that influence employees' decisions to stay or leave. Following that, factor analysis is used. According to Thevanes \& Harikaran, (2020), turnover is defined as members who leave the organization for opportunities that are more suitable than their current jobs. Employees who leave the organization either on their own initiative or at the request of others cause problems for the organization. The organization suffers a loss of investment in training and selecting such employees. The turnover is the result of coworkers' and supervisors' attitudes and behaviors on the job, and in every state of affairs, the intention of quitting becomes dependent on various factors, and turnover becomes an opposite dependent variable to predict the actual intentions of quitting. The turnover rate rises as the intention to quit rises.

Van der Heijden et al., (2018) used self-concept theory to explain more variation in employee turnover. The personality traits allow the researchers to gain a better understanding of the causes of turnover and the collision of each attribute on it. Following that, she proposed that the individual level of self-concept is positively associated with turnover intent, while the collective level of self-concept is negatively associated. The turnover intention is a person's intention to leave not only the location but also the job, role, and work environment (Ola et al., 2019).

Cho et al., (2019), defined turnover intention as employees' willingness and likelihood of remaining in the organization by adopting a more positive attitude. Turnover intention focuses not only on retaining an organization's critical talent, but also on instilling positive work behavior in its members. Employee turnover intention, as defined by (Amalia \& Zakiy, 2021), is defined as employees' desire to remain members of the organization or their willingness to stay in the organization. Panojan et al., (2019), defined turnover intention as an employee's willingness to remain in the organization after careful consideration. According to Ludiya, (2018), turnover intention refers to employees' willingness to stay in the organization and work with their coworkers. However, Els et al., (2021), argued that turnover intention is concerned with employees' loyalty to their organizations' work conditions and environment, as well as their willingness to continue working with colleagues in their organizations.

Today's business organizations are dealing with a major issue: key employees are leaving the organization. Employee turnover has always been a source of concern for businesses. It is a serious issue, particularly in the field of human resource management. A high level of employee turnover may be detrimental to both the organization and the employee's career (Bontrager et al., 2021). The number of employees who have expressed a desire to leave is causing issues by eroding internal HR strength. The intention of an employee to leave the organization is referred to as TI. In other words, the intention to leave a job precedes the actual departure. As a result, employee retention is a critical component of any company's longterm competitive advantage (Al Doghan, 2020). Moquin et al., (2019) defined three dimensions for TI measurement. Researchers define TI as an attitudinal (considering quitting), decisional (planning to leave), and behavioral (looking for a new job) process. It is critical to keep skilled employees on the job for as long as possible. Employees' TI, according to previous researchers, arises as a result of a role conflict between dual careers. As a result, the organization's employee retention strategy based on a work-life balance approach is critical (Romeo et al., 2020).

\section{RESEARCH METHODOLOGY}

\section{Research Strategy and Design}

The overall strategy used to carry out research that defines a succinct and logical plan to tackle established research questions through data collection, interpretation, analysis, and discussion is referred to as research design. A research design's purpose is to provide a study plan that allows for accurate assessment of cause-and-effect relationships between independent and dependent variables. The traditional controlled experiment is an excellent example of good research design. A well-planned research design helps 
ensure that your methods correspond to your research objectives, that you collect high-quality data, and that you use the appropriate type of analysis to answer your questions, using credible sources.

In this study the quantitative research method used to measure the influence of interpersonal conflict, job stress, and work life balance on employee turnover intention. Quantitative research methods emphasize objective measurements and statistical, mathematical, or numerical analysis of data gathered through polls, questionnaires, and surveys, or by manipulating pre-existing statistical data with computational techniques. The goal of quantitative research is to gain a better understanding of the social world. Quantitative methods are used by researchers to observe situations or events that have an impact on people. Quantitative research generates objective data that can be communicated clearly using statistics and numbers. The goal of quantitative research is to gain a better understanding of the social world. Quantitative methods are used by researchers to observe situations or events that have an impact on people. Quantitative research generates objective data that can be communicated clearly using statistics and numbers.

\section{Sample Size}

Sampling is the selection of a subset of individuals from a statistical population to estimate characteristics of the entire population in statistics, quality assurance, and survey methodology. Statisticians make an effort to collect samples that are representative of the population under consideration. In general, sampling allows researchers to collect enough data to answer the research question(s) without having to poll the entire population, which saves time and money. The sampling method, however, varies depending on whether the study is quantitative or qualitative. Power analysis (typically using G*Power3 or something similar) and random selection are the two pillars of quantitative sampling. Power analysis is used to calculate the smallest sample size required to ensure that the sample and data are statistically significant. Random sampling is required to ensure that there is no bias and that the sample accurately represents the entire population. It is important to note that for random sampling to work, the sample must be drawn from a known population, so that every Nth person or item can be chosen at random. Qualitative sampling required far fewer participants than quantitative sampling because the goal is data saturation, or when themes begin to repeat within each subsequent participant response during the data analysis phase, rather than statistical significance. The number of participants required for data saturation varies according to experts, but it is usually between 10 and 25. Furthermore, for qualitative data collection, random sampling is typically not required or appropriate, but rather convenience or purposeful. Purposive appears to be the preferred approach of the two because participants are targeted based on their specific demographics.

When a researcher uses random sampling, he or she ensures that every member of the population being studied has an equal chance of being chosen to participate in the study. Importantly, "the population being studied" does not always refer to the entire population of a country or region. A population, on the other hand, can refer to people who share a common quality or characteristic.

A random sampling method was used to gather data. The researchers distribute 120 questionnaires. 112 questionnaires were received but only 104 questionnaires were valid. The questionnaire was in multiple choice format questions. The respondents were asking to rate each question according to five-point likert, ranging from $1=$ strongly disagree, $2=$ disagree, $3=$ neutral, $4=$ agree and $5=$ strongly agree.

\section{Data collection}

Data collection is the process of gathering and measuring information on specific variables in an established system, allowing one to answer pertinent questions and evaluate outcomes. Data collection is an essential component of research in all fields of study, including physical and social sciences, humanities, and business. The primary goal of data collection is to collect information in a measured and systematic manner in order to ensure accuracy and facilitate data analysis. Because the data gathered is intended to provide content for data analysis, the information gathered must be of the highest quality to be valuable. The correct and organized method of obtaining studies is referred to as data collection. It assists you in acquiring the necessary fundamental knowledge of your field of study. It is regardless of whether it is business, governmental, or academic. The data collection process is critical to moving forward with any research or field, whether in science, humanities, or business planning. The research's longevity is jeopardized if the data collected is insufficient and credible. When individuals or organizations begin data collection, they should be prepared to spend countless hours and efforts inefficiently collecting because it appears to be one of the most difficult and critical parts of the job. The data collection process is closely related to one another. The same is true even if the aim or goal does not align. In this study, the mail survey was used to collect the data to examine the influence of the influence of interpersonal conflict, job stress, and work life balance on employee turnover intention. This method of data collection can reach anyone and everyone without any barriers, but it can also be costly, with lag time and data-collection errors. 


\section{Conceptual Framework}

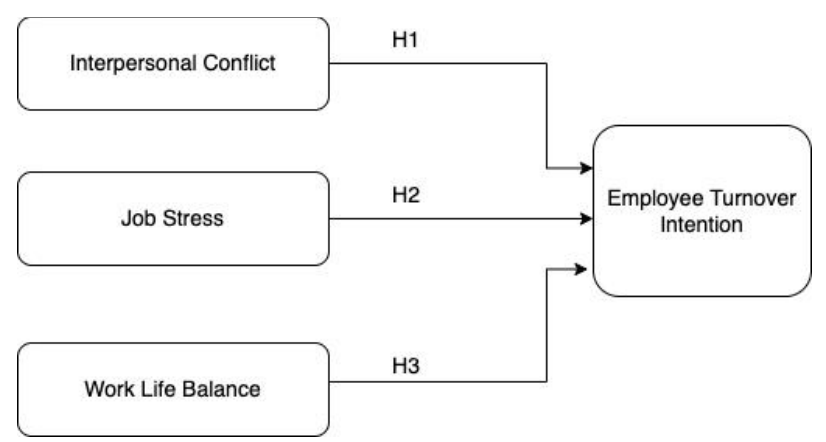

Figure 1: Conceptual Framework

\section{Research Hypotheses}

Hypothesis -1-: Interpersonal conflict has a positive and significant influence on employee turnover intention.

Hypothesis -2-: Job stress has a positive and significant influence on employee turnover intention.

Hypothesis -3-: Work life balance has a positive and significant influence on employee turnover intention.

\section{Data Analysis}

Table 1: Reliability Statistics

\begin{tabular}{|l|l|l|}
\hline Factors & $\begin{array}{l}\text { Cronbach's } \\
\text { Alpha }\end{array}$ & N of Items \\
\hline Interpersonal conflict & .791 & 7 \\
\hline Job stress & .816 & 7 \\
\hline Work life balance & .765 & 9 \\
\hline $\begin{array}{l}\text { Employee turnover } \\
\text { intention }\end{array}$ & .794 & 10 \\
\hline
\end{tabular}

Table (1) shows the reliability statics analysis. The researchers used four independent factors (Interpersonal conflict, Job stress, and Work life balance) on the other hand, one dependent factor (employee turnover intention). In terms of Interpersonal conflict as independent factor, the Cronbach's Alpha $=.791$ for 7 items, since $(.791<.6)$ therefore 7 Interpersonal conflict questions were reliable. In terms of Job stress as independent factor, the Cronbach's Alpha $=.816$ for 7 items, since $(.816<.6)$ therefore $7 \mathrm{Job}$ stress questions were reliable. In terms of Work life balance as independent factor, the Cronbach's Alpha $=.765$ for 9 items, since $(.765<.6)$ therefore 9 Work life balance questions were reliable. The reliability test for employee turnover intention as dependent factor, the Cronbach's Alpha $=.794$ for 10 items, since $(.794<.6)$ therefore, 10 employee turnover intention questions were reliable.

Table 2: Correlations Analysis

\begin{tabular}{|l|l|l|l|l|}
\hline Items & Pearson Correlation & $\begin{array}{l}\text { Interpersonal } \\
\text { conflict }\end{array}$ & Job stress & $\begin{array}{l}\text { Work life } \\
\text { balance }\end{array}$ \\
\hline \multirow{2}{*}{$\begin{array}{l}\text { Interpersonal } \\
\text { conflict }\end{array}$} & Pearson correlation & 1 & $.839^{* *}$ & $.872^{* *}$ \\
\cline { 2 - 5 } & Sig. (2-tailed) & & .000 & .000 \\
\cline { 2 - 5 } & $\mathrm{N}$ & 104 & 104 & 104 \\
\hline \multirow{3}{*}{ Job stress } & Pearson Correlation & $.839^{* *}$ & 1 & $.861^{* *}$ \\
\cline { 2 - 5 } & Sig. (2-tailed) & .000 & 104 & .000 \\
\cline { 2 - 5 } & $\mathrm{N}$ & 104 & $.861^{* *}$ & 104 \\
\hline \multirow{2}{*}{ Work life balance } & Pearson Correlation & $.872^{* *}$ & .000 & 104 \\
\hline & Sig. (2-tailed) & .000 & 104 & $.632^{* *}$ \\
\hline \multirow{2}{*}{$\begin{array}{l}\text { Customers' } \\
\text { behaviour }\end{array}$} & $\mathrm{N}$ & 104 & $.685^{* *}$ & .000 \\
\cline { 2 - 5 } & Pearson Correlation & $.595^{* *}$ & .000 & 104 \\
\cline { 2 - 5 } & Sig. (2-tailed) & .000 & 104 & \\
\cline { 2 - 5 } & $\mathrm{N}$ & 104 & & 104 \\
\hline
\end{tabular}

**. Correlation is significant at the 0.01 level (2-tailed). 
Table (2) shows the correlation analysis. As mentioned previously four independent factors (Interpersonal conflict, Job stress, and Work life balance) were analyzed and one dependent factor (employee turnover intention). As seen in the above table, the Pearson Correlation for Interpersonal conflict $=.595^{* *}($ Correlation is significant at the 0.01 level, 2-tailed), therefore there is a strong positive correlation between Interpersonal conflict and employee turnover intention. The Pearson Correlation for Job stress $=.685^{* *}$ (Correlation is significant at the 0.01 level, 2-tailed), therefore there is a strong positive correlation between Job stress and employee turnover intention. The Pearson Correlation for Work life balance $=.632 * *$ (Correlation is significant at the 0.01 level, 2-tailed), therefore there is a strong positive correlation between Work life balance and employee turnover intention.

Table 3: Model Summary

\begin{tabular}{|l|l|l|l|l|}
\hline Model & $\mathrm{R}$ & R Square & Adjusted R Square & Std. Error of the Estimate \\
\hline 1 & $.926 \mathrm{a}$ & .858 & .853 & .28625 \\
\hline \multicolumn{4}{|l|}{ a. Predictors: (Constant), Interpersonal conflict, Job stress, Work life balance } \\
\hline
\end{tabular}

Table (3), shows the value of $\mathrm{R}$ square $=.858$, which indicates that $86 \%$ of the variables have been explained.

Table 4: ANOVA

\begin{tabular}{|l|l|l|l|l|l|l|}
\hline Model & & Sum of squares & Df & Mean Square & F & Sig. \\
\hline & Regression & 55.574 & 4 & 13.893 & 169.553 & $.000 \mathrm{~b}$ \\
\hline 1 & Residual & 9.177 & 112 & .082 & & \\
\hline & Total & 64.751 & 116 & & & \\
\hline
\end{tabular}

a. Dependent Variable: Employee turnover intention

b. Predictors: (Constant), Interpersonal conflict, Job stress, Work life balance

Table (4) shows the value of $\mathrm{F}$ for four independent factors and a dependent factor is $169.553>1$ which indicates there is a significant association between four independent factors and dependent factor.

Table 5: Coefficients

\begin{tabular}{|l|l|l|l|l|l|l|}
\hline Model & & \multicolumn{2}{|l|}{ Unstandardized Coefficients } & $\begin{array}{l}\text { Standardized } \\
\text { Coefficients }\end{array}$ & $\mathrm{t}$ & Sig. \\
\hline 1 & & $\mathrm{~B}$ & Std. Error & Beta & & \\
\cline { 2 - 8 } & (Constant) & .345 & .179 & & 1.929 & .056 \\
\cline { 2 - 7 } & Interpersonal conflict & .611 & .092 & .619 & .739 & .000 \\
\cline { 2 - 7 } & Job stress & .599 & .075 & .604 & 2.878 & .000 \\
\cline { 2 - 7 } & Work life balance & .643 & .087 & .649 & 2.121 & .000 \\
\hline
\end{tabular}

a. Dependent Variable: Employee Turnover Intention

Table (5) shows multiple regression analysis. As seen the results of multiple regression analysis, the value $B$ for Interpersonal conflict factor is .611 (.611>0.01) therefore first research hypothesis was supported. The value B for Job stress factor is $.599(.599<0.01)$ therefore second research hypothesis was supported. The value B for Work life balance factor is $.643(.643>0.01)$ therefore third research hypothesis was supported.

\section{DISCUSSION}

Interpersonal conflict and job stress were found to have positive relationships with turnover intentions in this study. 
The findings and data provide empirical support for the facts detailed in the literature review. Since there is no one-sizefits-all solution to the issue of work-life conflict, different policies, practices, and strategies will be required to reduce the work-life conflict investigated in his study (Ali \& Anwar, 2021). A company would implement a strategy that would reduce the symptoms of interpersonal conflict and the causes of job stress. Interpersonal conflicts should be investigated in the future, for example, in terms of styles and consequences in different functional areas, as well as across different cultures and countries. This society's cultural differences have collided abruptly. As a result, policies, practices, and organizational strategies differ from one organization to the next. Work overload and work-to-family conflict, according to Abdullah et al., (2017), did not have a significant correlation with turnover intentions in his sample. People do not want to change their current policies, timetables, or daily routines, which leads to turnover intentions. Lack of awareness, as well as a lack of job satisfaction and commitment, leads to a lack of job involvement, which leads to turnover in the long run. According to Hamad et al., (2021), perceiving oneself as more bureaucratic and management as more enthusiastic are related to positive employee outcomes because these views serve to increase an employee's sense of integration with the organization. If every employee is given the opportunity to develop himself and his work within the organization, the turnover ratio will be drastically reduced. Because the work environment is changing, job stress rises. Apparently difficult business plans, organizational new practices, and programs frequently put marketing executives in a stressful state. It is not easy for our marketing executives to maintain a significant amount of resistance at every step. Because if these individuals are job stressed out of their tasks and duties, they will be dissatisfied with their job, the environment of their organization, will not seek their own colleagues satisfactorily, and will thus have an impact on the organizational culture. Individuals who report experiencing at least some job stress in their current position are $25 \%$ more likely to intend to quit than those who do not, with the likelihood of intending to quit increasing with increasing job stress (Qader et al., 2021). Marketing executives strive to stay competitive in the market because their sphere of influence is vast and varied. They devise progressive and long-term strategies for achieving customer satisfaction. Being constantly active, progressive, and competitive places mental strain and work-related stress on these individuals. Some people become disappointed and frustrated when they are unable to generate desired revenue. Then they become overly stressed at work and are more likely to leave. Understanding of the organizational environment and the relationship between the members of the organization is critical for the effective functioning of the areas, including marketing (Hamza et al., 2021). If workers who are frequently exposed to job stress have a high turnover rate and absenteeism, more research on the subject would enable active job stress management policies to be more beneficial to individuals and the economy as a whole (Anwar \& Abdullah, 2021).

\section{CONCLUSION}

The goal of this study was to investigate the negative effects of interpersonal conflict and Job stress of organizational politics, as well as the possible antecedents of behavioral outcomes. By doing so, this study attempted to link different streams of research in organizational behavior such as interpersonal conflict, Job stress of politics, job stress, organizational deviance, interpersonal deviance, and intention to quit. This study broadens the negative consequences of conflict in a variety of ways. For starters, this study provided strong empirical evidence for interpersonal conflict, political Job stress, and outcomes such as workplace deviance, job stress, and intention to quit. Second, by relating interpersonal conflict to Job stresss of politics and job stress, current studies have established that interpersonal conflict in organizations leads to politics and creates job stress, both of which have negative consequences for individuals and the organization. Although there are numerous negative consequences of politics, the important factors that link conflict and politics are rarely investigated. To the best of my knowledge, this is the first study to assess the mediating role of political Job stress in relation to conflict and job outcomes.

The findings revealed that the value $\mathrm{B}$ for Interpersonal conflict factor is $.611(.611>0.01)$ therefore first research hypothesis was supported. The value B for Job stress factor is $.599(.599<0.01)$ therefore second research hypothesis was supported. The value B for Work life balance factor is $.643(.643>0.01)$ therefore third research hypothesis was supported. Although the literature shows that turnover has a negative impact on many organizations, this study provides evidence that this relationship has an impact on the pesticide sector in this region. The study also fills a research gap and improves Job stresss of the relationship between turnover intention and work job stress in general. It also contributes to the literature by including a conceptual framework for the relationship between job stress and intention to leave. This impact has not been thoroughly investigated in previous research in the same context, and this study empirically tests it. It is concluded that job stress has an effect on employees' intentions to leave. The findings are also consistent with previous research. 
The research gives researchers and practitioners in this field deep insight into the collision of job stressors on employees' turnover intentions and provides a guideline or baseline for the enhancement of various job factors, skills, supervisory support, and work overload. The study is also a source of secondary data for researchers in this field who want to study the effects of job stress in other dimensions on employees' intention to leave. Although the results are valuable, the limitations must be considered. To begin, this study considered a few job stressors such as career opportunities, work relationships, and other job factors such as working hours, working environment, work loads, and managers' assistance. The findings of this study will provide researchers and policymakers with information on the Employees' Turnover Intention and the problems encountered by the Pesticide Sector of Vehari District. This study should only be regarded as an exploratory study to investigate the observable fact of turnover intention in this sector. This study is expected to pave the way for researchers to conduct research in the same settings using different variables to examine the impact of job stress on employees' intention to leave. Existing market drifts in this area may differ from market drifts in other cities, and as a result, employee goals will change. Males make up the majority of our study's respondents, and their turnover intentions differ from those of females. Because intentions vary from society to society, the results will differ if respondents come from different cities and countries. Furthermore, if there are a large number of females, the outcome will be different. The replication of the findings in future studies would provide confirmation of the relationship under investigation.

This study adds to a small but important body of research on the effects of work-life imbalance and burnout on faculty retention and career satisfaction. The findings suggest that academic institutions and organizations should pay close attention to the causes of burnout and associated symptoms, as well as ensure that concrete and proactive approaches and mechanisms are in place to mitigate the effects of psychological job stress and burnout on faculty mental health and wellness, particularly during and after a pandemic. With current nursing practice and faculty workforce shortages, every effort must be made to create healthy work environments in order to retain satisfied and productive faculty, as this has ramifications for the quality of student training, mentoring, and quality research to advance nursing practice globally. Promoting work-life balance and workload management, such as reducing teaching assignments and service commitments, allowing adequate time for research activities, and pausing the tenure clock for pre-tenured faculty, is a good place to start when it comes to improving faculty satisfaction, retention, and career longevity. According to the study's findings, key implications for reducing employee TI of operational employees in the apparel sector have been identified. Furthermore, these suggestions can be used to reduce the employee's interpersonal conflict and improve their turnover intention. To begin, managers should be aware of employee interpersonal conflict and reduce their work load. Managers must identify employees' work-related issues and provide the best solution for them. Because employees prefer to work with friendly staff and management. An employee with an infant child, for example, dislikes working night shifts. Managers must provide an acceptable and friendly solution to her in this situation. Second, it is preferable to improve employee benefits based on their service time and experiences. The apparel industry offers attractive benefits to their employees based on their performance. Employees in the apparel industry, on the other hand, must work hard to meet their goals. It improves employees' interpersonal conflicts and employee turnover. As a result, the researcher proposed implementing a service period-based benefit system to motivate and retain employees in the organization. Third, it is ideal to establish welfare unions to provide employees with special benefits. Apparel can sometimes be a strategic business unit of a large corporation. In this case, the company can make special offers to its employees via other business units. The company can establish welfare unions to foster relationships among all employees.

\section{REFERENCES}

[1] Aboobaker, N., \& Edward, M. (2020). Collective influence of work-family conflict and work-family enrichment on turnover intention: exploring the moderating effects of individual differences. Global Business Review, 21(5), 12181231.

[2] Afzal, H. F., Islam, K. A., Ismail, A., Tahir, M. Y., Zohaib, M., Riaz, J., \& Ismail, M. (2021). The role of underemployment in turnover intention through job deprivation and job stress: a multiple mediation mechanism. International Journal of Business and Management Future, 5(1), 27-37.

[3] Abdullah, M. S., Toycan, M., \& Anwar, K. (2017). The cost readiness of implementing e-learning. Custos E Agronegocio On Line, 13(2), 156-175.

[4] Al Doghan, M. A. (2020). Employees Work Stress in Saudi Telecom Sector: Examining the Role of Long Working Hours, Empowerment, Work Life Balance and Work Environment. Journal of Economics, Management and Trade, 26(2), 81-91.

[5] Ali, B. J., \& Anwar, G. (2021). An Empirical Study of Employees' Motivation and its Influence Job Satisfaction. Ali, BJ, \& Anwar, G.(2021). An Empirical Study of Employees' Motivation and its Influence Job Satisfaction. 
International Journal of Engineering, Business and Management, 5(2), 21-30.

[6] Alias, N. E., Rohmanan, N. H., Ismail, S., Koe, W. L., \& Othman, R. (2018). Factors influencing turnover intention in a Malaysian manufacturing company. KnE Social Sciences, 771-787.

[7] Amalia, D. P., \& Zakiy, M. (2021). Working Period As A Moderating Variable Of Work Family Conflict, Work Stress, And Turnover Intention On Counterproductive Work Behavior. Perisai: Islamic Banking and Finance Journal, 5(2), 202-212.

[8] Andrade, M. S., Miller, D., \& Westover, J. H. (2021). Job satisfaction in the hospitality industry: The comparative impacts of work-life balance, intrinsic rewards, extrinsic rewards, and work relations. American Journal of Management, 21(2), 39-56.

[9] Anwar, G., \& Abdullah, N. N. (2021). The impact of Human resource management practice on Organizational performance. International journal of Engineering, Business and Management (IJEBM), 5.

[10] Bontrager, M., Clinton, M. S., \& Tyner, L. (2021). Flexible work arrangements: a human resource development tool to reduce turnover. Advances in Developing Human Resources, 23(2), 124-141.

[11] Califf, C. B., \& Brooks, S. (2020). An empirical study of techno-stressors, literacy facilitation, burnout, and turnover intention as experienced by $\mathrm{K}-12$ teachers. Computers \& Education, 157, 103971

[12] Chang, H. P., Hsieh, C. M., Lan, M. Y., \& Chen, H. S. (2019). Examining the moderating effects of work-life balance between human resource practices and intention to stay. Sustainability, 11(17), 4585.

[13] Cho, J., Lee, H. E., \& Kim, H. (2019). Effects of communication-oriented overload in mobile instant messaging on role stressors, burnout, and turnover intention in the workplace. International Journal of Communication, 13, 21.

[14] Chuan-Chiew, G., Hwa, M. A. C., \& Teh, G. M. (2018). Work intensification and turnover intention in academia: The mediating role of work-life balance. Journal of Asian Scientific Research, 8(5), 188-196.

[15] Els, V., Brouwers, M., \& Lodewyk, R. B. (2021). Quality of work life: Effects on turnover intention and organisational commitment amongst selected South African manufacturing organisations.SA Journal of Human Resource Management, 19, 1407.

[16] Fadillah, A. R., Aras, R. A., \& Wahyuni, S. (2022, February). The Effects of Work-Life Balance Towards Work Stress Among Nurses. In Interdisciplinary Conference of Psychology, Health, and Social Science (ICPHS 2021) (pp. 232-238). Atlantis Press.

[17] Gholitabar, S., Costa, C., \& Tourian, F. (2020). Determinants of burnout and turnover intention in travel agencies (Iran): the investigation of familywork conflict, nepotism and customer aggression on employees' performance. Revista Turismo \& Desenvolvimento, (34), 139-148.

[18] Giao, H. N. K., Vuong, B. N., Huan, D. D., Tushar, H., \& Quan, T. N. (2020). The effect of emotional intelligence on turnover intention and the moderating role of perceived organizational support: Evidence from the banking industry of Vietnam. Sustainability, 12(5), 1857.

[19] Gim, G. C., \& Ramayah, T. (2020). Predicting turnover intention among auditors: is WIPL a mediator?. The Service Industries Journal, 40(9-10), 726-752.

[20] Gragnano, A., Simbula, S., \& Miglioretti, M. (2020). Worklife balance: Weighing the importance of work-family and work-health balance. International journal of environmental research and public health, 17(3), 907.

[21] Haar, J., \& Brougham, D. (2020). Work antecedents and consequences of work-life balance: A two sample study within New Zealand. The International Journal of Human Resource Management, 1-24.

[22] Hamad, H. A., Qader, K. S., Gardi, B., Abdalla, P., Hamza, D., \& Anwar, G. (2021). The essential variables to consider before investing in financial markets during Covid-19.

[23] Hamza, P. A., Hamad, H. A., Qader, K. S., Gardi, B., \& Anwar, G. (2021). Management of outsourcing and its relationship with hotels' performance: An empirical analysis of selected hotels in Erbil. International Journal of Advanced Engineering Research and Science, 8, 10.

[24] Holland, P., Tham, T. L., Sheehan, C., \& Cooper, B. (2019). The impact of perceived workload on nurse satisfaction with work-life balance and intention to leave the occupation. Applied nursing research, 49, 70-76.

[25] Hutagalung, I., Soelton, M., \& Octaviani, A. (2020). The role of work life balance for organizational commitment. Management Science Letters, 10(15), 36933700 .

[26] Irawanto, D. W., Novianti, K. R., \& Roz, K. (2021). Work from home: Measuring satisfaction between work-life balance and work stress during the COVID-19 pandemic in Indonesia. Economies, 9(3), 96.

[27] Jiang, H., \& Shen, H. (2018). Supportive organizational environment, work-life enrichment, trust and turnover intention: A national survey of PRSA membership. Public Relations Review, 44(5), 681-689.

[28] Kim, H., \& Kim, E. G. (2021). A meta-analysis on predictors of turnover intention of hospital nurses in South Korea (2000-2020). Nursing Open, 8(5), 2406-2418.

[29] Lestari, D., Tricahyadinata, I., Rahmawati, R., Darma, D. C., Maria, S., \& Heksarini, A. (2021). The concept of work-life balance and practical application for customer services of bank. Jurnal Minds: Manajemen Ide dan Inspirasi, 8(1), 155174.

[30] Li, J. C., Cheung, C. K., Sun, I. Y., Cheung, Y. K., \& Zhu, S. (2021). Work-Family Conflicts, Stress, and Turnover Intention Among Hong Kong Police Officers Amid the COVID-19 Pandemic. Police Quarterly, 10986111211034777.

[31] Ludiya, H. (2018). Pengaruh Work Life Policies, Work Life Conflict, Job Stress, dan Loneliness terhadap Turnover Intentions pada sebuah Universitas Swasta di Kota Batam. Jurnal Manajemen dan Pemasaran Jasa, 9(2), 299322. 
[32] Mallika, G., \& Das, V. T. (2020). Impact of Stress on working performance of Nurses and Organizational effectiveness in Hospitals. Asian Journal of Management, 11(3), 225-232.

[33] Mohd Pauzi, N., Shari, A. S., Ismail, H. F., Luqman, A., Sakarji, S. R., Wan Azib, W. N. H., \& Subahudin, S. N. A. (2021). A preliminary study of job stress factors on job satisfaction among government employees in Malaysia's southern region. Social and Management Research Journal (SMRJ), 18(2), 133-151.

[34] Moquin, R., K. Riemenschneider, C., \& L. Wakefield, R. (2019). Psychological contract and turnover intention in the information technology profession. Information Systems Management, 36(2), 111-125.

[35] Mullen, P. R., Malone, A., Denney, A., \& Santa Dietz, S. (2018). Job stress, burnout, job satisfaction, and turnover intention among student affairs professionals. College Student Affairs Journal, 36(1), 94-108.

[36] Naig, A. M. J., \& Borbon, N. M. D. Work-Life Balance, Experience and Organizational Commitment among Restaurant Employees in Central Luzon Region: Basis for Proposed Framework. Development, 9(2), 114-129.

[37] Navajas-Romero, V., Ariza-Montes, A., \& HernándezPerlines, F. (2020). Analyzing the job demands-controlsupport model in work-life balance: A study among nurses in the European context. International journal of environmental research and public health, 17(8), 2847.

[38] Ola, O. O., John, W. O., Simeon, O. A., \& Mutiu, O. A. (2019). Impact of work life balance on the social life of workers living in Lagos metropolitan borders. Annals of Contemporary Developments in Management \& $H R$ (ACDMHR) Vol, 1, 50-59.

[39] Panojan, P., Perera, B. A. K. S., \& Dilakshan, R. (2019). Work-life balance of professional quantity surveyors engaged in the construction industry. International Journal of Construction Management, 1-18.

[40] Park, I. J., Kim, P. B., Hai, S., \& Dong, L. (2020). Relax from job, Don't feel stress! The detrimental effects of job stress and buffering effects of coworker trust on burnout and turnover intention. Journal of Hospitality and Tourism Management, 45, 559-568.

[41] Pathak, R. R. (2018). Work life balance in Nepalese commercial banks. Journal of Business and Social Sciences, 2(1), 116-125.

[42] Perumal, G., Sinniah, S., Mohamed, R. K. M. H., Mun, K. P., \& Murthy, U. (2018). Turnover intention among manufacturing industry employees in Malaysia: An analysis using Structural Equation Modeling (SEM). e-BANGI, 13(4), 13-24.

[43] Qader, K. S., Hamad, H. A., Gardi, B., Abdalla, P., Hamza, D., \& Anwar, G. (2021). The role of sophisticated accounting system in organizational planning.

[44] Raharjo, K., Fiernaningsih, N., Nimran, U., \& Arifin, Z. (2019). Impact of work-life balance and organisational citizenship behaviour on intention to leave. International Journal of Innovation, Creativity and Change, 8(4), 95-113.

[45] Romeo, M., Yepes-Baldó, M., \& Lins, C. (2020). Job satisfaction and turnover intention among people with disabilities working in Special Employment Centers: The moderation effect of organizational commitment. Frontiers in Psychology, 11, 1035.

[46] Saerang, Y. B., Zamralita, M., \& Saraswati, K. D. (2020, May). The Role of Psychological Capital, Quality of Work Life, and Perceived Job Opportunity on Turnover Intention in Millennials (Study on PT. X Business Unit). In Tarumanagara International Conference on the Applications of Social Sciences and Humanities (TICASH 2019) (pp. 534-541). Atlantis Press.

[47] Son, D. M., \& Ham, O. K. (2020). Influence of group resilience on job satisfaction among Korean nurses: A crosssectional study. Journal of Clinical Nursing, 29(17-18), 3473-3481.

[48] Thevanes, N., \& Harikaran, S. (2020). Work-Life Balance and Organizational Performance: The Mediating Role of Organizational Citizenship Behavior. Asian Journal of Social Sciences and Management Studies, 7(4), 280-287.

[49] Van der Heijden, B. I., Peeters, M. C., Le Blanc, P. M., \& Van Breukelen, J. W. M. (2018). Job characteristics and experience as predictors of occupational turnover intention and occupational turnover in the European nursing sector. Journal of Vocational Behavior, 108, 108-120.

[50] Vasumathi, A., Sagaya, M. T., \& Poranki, K. R. (2019). The impact of emotional intelligence on work life balance among the faculty members' performance in the private universities using multivariate analysis, Tamil Nadu, India-an empirical study. International Journal of Services and Operations Management, 34(1), 1-20.

[51] Viegas, V., \& Henriques, J. (2021). Job stress and workfamily conflict as correlates of job satisfaction among police officials. Journal of Police and Criminal Psychology, 36(2), 227-235.

[52] Wood, J., Oh, J., Park, J., \& Kim, W. (2020). The relationship between work engagement and work-life balance in organizations: A review of the empirical research. Human Resource Development Review, 19(3), 240-262.

[53] Yildiz, B., Yildiz, H., \& Ayaz Arda, O. (2021). Relationship between work-family conflict and turnover intention in nurses: A meta-analytic review. Journal of Advanced Nursing, 77(8), 3317-3330.

[54] Zahra, S. S., Khan, M. I., Imran, M., Aman, Q., \& Ali, R. (2018). The relationship between job stress and turnover intentions in the pesticide sector of Pakistan: An employee behavior perspective. Management Issues in Healthcare System, 4, 1-12.

[55] Zhou, S., Li, X., \& Gao, B. (2020). Family/friends support, work-family conflict, organizational commitment, and turnover intention in young preschool teachers in China: A serial mediation model. Children and youth services review, 113, 104997. 